\title{
Thyroid Crisis and Septic Suspected Sepsis in the First Trimester of Pregnancy
}

\author{
Mahmudah Hidayati ${ }^{1}$, Banundari Rachmawati ${ }^{2}$ \\ ${ }^{1}$ Clinical Pathology Subspecialist Program, Faculty of Medicine, Diponegoro University/Dr. Kariadi Hospital, Semarang, Indonesia. E-mail: \\ hidayati.mahmudah@gmail.com \\ ${ }^{2}$ Department of Clinical Pathology, Faculty of Medicine, Diponegoro University/Dr. Kariadi Hospital, Semarang, Indonesia
}

\begin{abstract}
A normal pregnancy with physiological and hormonal changes can change thyroid function, accordingly, there are difficulties to establish the diagnosis of thyroid abnormality. The prevalence of hyperthyroidism in pregnancy is $0.6 \%$. Approximately $1-2 \%$ of hyperthyroidism develops into a thyroid crisis. Knowledge of the diagnosis of the thyroid crisis in a pregnant female is very important to avoid complications. The 22-years-old female of thirteen weeks presented with vomiting, since two days before hospitalized, weakness, and decreased consciousness. During treatment, patients had diarrhea, melena, and was irritable. Physical examination showed blood pressure of 136/112 mmHg, pulse of 110 times/minute, respiration of 24 times/minute, and temperature of $38.3^{\circ} \mathrm{C}$. Exophthalmos was found the patient's eyes, but there was no enlargement of the thyroid and the patient often screamed hysterically. Routine urine examination showed proteinuria $1+$, blood $3+$, leukocytes 1+ in urinalysis, FT4 35.18 pmol/L and TSH <0.05 uIU/mL, leukocytes 15.2 x103/uL, SGOT 245 U/L, SGPT 366 U/L. The final diagnosis of this patient is a thyroid crisis and suspect sepsis in the first trimester of pregnancy. Thyroid Receptor Antibody (TRAb) examination should be performed to assure Graves disease or hyperthyroidism due to pregnancy (transient hyperthyroidism) as the cause.
\end{abstract}

Keywords: Pregnancy, hyperthyroidism, thyroid crisis, sepsis

\section{INTRODUCTION}

Hyperthyroidism is a clinical and biochemical condition that shows elevated levels of the thyroid hormone. ${ }^{1,2}$ Symptoms of hyperthyroidism include weight loss, unstable emotions, irregular heart rhythm, tremor, insomnia, hair loss, diarrhea, etc. ${ }^{2}$

A normal pregnancy with physiological and hormonal changes can alter thyroid function; therefore, laboratory tests of thyroid function must be interpreted with caution during pregnancy. ${ }^{3}$ Establishment of disease diagnosis or identification of thyroid abnormalities becomes difficult. ${ }^{1}$

The prevalence of hyperthyroidism in pregnancy is $0.6 \%{ }^{4}$ The incidence of hyperthyroidism is higher in the first trimester of pregnancy $[1.50$ (95\% CI 1.09-2.06)] and more common in the first pregnancy compared to the next pregnancy. ${ }^{3}$

Of all cases, the most common cause (80-85\%) of maternal hyperthyroidism during pregnancy is Graves' disease, and it is found in 1 from 1500 pregnant patients. Another common cause of hyperthyroidism is high HCG levels which can be observed as hyperemesis gravidarum which can cause transient hyperthyroidism. ${ }^{5,6}$
The thyroid crisis is a rare but very serious condition, potentially life-threatening in people with untreated hyperthyroidism. Approximately $1-2 \%$ of hyperthyroidism develops into a thyroid crisis. ${ }^{7}$ It can also be triggered by surgery, trauma, or infection. ${ }^{2.8,9}$ Sepsis can induce thyroid crisis, and the initial symptoms of sepsis are very similar to The thyroid crisis.

Hyperthyroidism in uncontrolled or untreated pregnancies can cause complications in infants, such as small size, which does not represent the gestational age, premature birth, stillbirth, and congenital abnormalities. Also, mothers can experience hypertension, preeclampsia, and thyroid crisis. ${ }^{2 ., 10}$ Symptoms of thyroid crisis is similar to hyperthyroidism, although it occurs quickly and is more severe.

Cases of thyroid crisis accompanied by sepsis in pregnancy are very interesting to discuss because they include extremely rare cases. Harmful complications for both mother and child can occur because it requires extensive knowledge in diagnosing, which ultimately results in faster and more appropriate management. 


\section{CASE}

22-year-old mother came with complaints of vomiting for two days before entering $\mathrm{Dr}$. $\mathrm{H}$. Soewondo Kendal. The patient vomited every time after eating/drinking 4-5 x/day. Vomiting was observed as previously consumed food/drink. The patient looked weak, and her consciousness decreased. The patient was thirteen weeks pregnant in the first pregnancy. The patient's and her family's history of thyroid disease were denied. Two months before entering the hospital, the patient complained about frequent vomiting and assumed it was natural due to pregnancy.

Physical examination showed blood pressure of $136 / 112 \mathrm{mmHg}$, heart pulse of $110 \mathrm{x} / \mathrm{m}$, respiration $24 \mathrm{x} / \mathrm{min}$, and temperature of $38.3^{\circ} \mathrm{C}$. Exophthalmos was observed in the patient's eyes, but no thyroid enlargement was seen, and the patient was frequently screaming. During treatment, the patient experiences diarrhea and melena.

The patient was diagnosed with G1P0A0 thirteen

Table 1. Laboratory tests during treatment

\begin{tabular}{|c|c|c|c|}
\hline Parameter & Results & Measurement Unit & Normal Value \\
\hline \multicolumn{4}{|l|}{ Hematology } \\
\hline Hemoglobin & 11.7 & $\mathrm{gr} / \mathrm{dL}$ & $11.5-16.5$ \\
\hline Hematocrit & 33.8 & $\%$ & $35-49$ \\
\hline Erythrocyte & 4.37 & $10^{6} / \mathrm{uL}$ & $4.4-5.9$ \\
\hline $\mathrm{MCH}$ & 25.9 & pg & $24.00-32.00$ \\
\hline MCV & 80.8 & $f \mathrm{~L}$ & $76-96$ \\
\hline $\mathrm{MCHC}$ & 32 & $\mathrm{~g} / \mathrm{dL}$ & $29-36$ \\
\hline Leukocyte & 15.2 & $10^{3} / \mathrm{mmk}$ & $4-10$ \\
\hline Thrombocyte & 247 & $10^{3} / \mathrm{mmk}$ & $150-400$ \\
\hline RDW & 16.7 & $\%$ & $11.6-14.8$ \\
\hline MPV & 8.5 & $\mathrm{fL}$ & $4.0-11.0$ \\
\hline \multicolumn{4}{|c|}{ Clinical chemistry } \\
\hline RBG & 204 & $\mathrm{mg} / \mathrm{dL}$ & $80-160$ \\
\hline Ureum & 202 & $\mathrm{mg} / \mathrm{dL}$ & $15-39$ \\
\hline Creatinin & 1.31 & $\mathrm{mg} / \mathrm{dL}$ & $0.6-1.3$ \\
\hline Calcium & 1.14 & $\mathrm{mmol} / \mathrm{L}$ & $1.13-1.31$ \\
\hline Sodium & 135 & $\mathrm{mmol} / \mathrm{L}$ & $136-145$ \\
\hline Potassium & 3.5 & $\mathrm{mmol} / \mathrm{L}$ & $3.5-5.1$ \\
\hline SGOT & 245 & $U / L$ & $12-37$ \\
\hline SGPT & 366 & $U / L$ & $12-41$ \\
\hline \multicolumn{4}{|c|}{ Thyroid hormone } \\
\hline FT4 & 35.18 & $\mathrm{pmol} / \mathrm{L}$ & $9-20$ \\
\hline TSH & $<0.05$ & $\mathrm{uIU} / \mathrm{ml}$ & $0.25-5.0$ \\
\hline \multicolumn{4}{|c|}{ Routine urine test } \\
\hline Color & Reddish & & Yellow - light yellow \\
\hline Blood & $3+$ & & Negative \\
\hline $\mathrm{pH}$ & 6.5 & & $4.8-7.8$ \\
\hline Specific gravity & 1.015 & & $1.003-1.030$ \\
\hline Protein & $1+$ & & Negative \\
\hline Leukocyte & $1+$ & & Negative \\
\hline Nitrite & Negative & & Negative \\
\hline \multicolumn{4}{|l|}{ Sediment : } \\
\hline Leukocyte & $4-6$ & & $0-5$ \\
\hline Erythrocyte & Full & & $0-2$ \\
\hline \multicolumn{4}{|c|}{ Immunoserology } \\
\hline Anti-HIV & Non-reactive & Non-reactive & \\
\hline HBsAg & Negative & Negative & \\
\hline
\end{tabular}


weeks pregnant with a thyroid crisis, and suspected sepsis. The patient was treated in the intensive care unit. Then management for patients was as follows: 3 liters $02 /$ minute, as much as 20 drops of Ringer's lactate solution per minute, 4 units blood transfusion (on the fourth day of treatment the patient had melena, and the $\mathrm{Hb}$ decreased to $7 \mathrm{gr} / \mathrm{dL}$ ), injection of Cefixime $200 \mathrm{mg}$ every 12 hours, Ranitidine $150 \mathrm{mg}$ orally two times a day, PTU orally three times a day, Propanolol $10 \mathrm{mg}$ orally three times a day, injection of Ondansetron Every 8 hours, and Folic acid orally once daily.

Patients showed improvement and were allowed to go home after being treated for nine days. The patient was recommended to consult with the Department of Obgyn and Internal Medicine. Two months after treatment, the patient felt healthy, and repeated complaints were not found. The patient decided to consult the nearest public clinic because the mother and her baby were declared healthy.

\section{DISCUSSIONS}

In this case, the patient was diagnosed with G1P0A0 thirteen weeks pregnant with a thyroid crisis and suspected sepsis. Based on the anamnesis, the patient was a 22-year-old mother with the first pregnancy and no history of miscarriage. Patients came with complaints of vomiting for two days before coming to the hospital. The patient looked weak, and her consciousness decreased. The patient's and her family's history of thyroid disease were denied. Two months before hospitalization, the patient complained about frequent vomiting.

Thyroid function tests change during pregnancy due to the influence of two main hormones, such as Human Chorionic Gonadotropin (HCG) and estrogen. Human chorionic gonadotropin slightly activates the thyroid, and high circulating HCG levels in the first trimester can produce TSH at a slightly low level (also known as subclinical hyperthyroidism). When this occurs, TSH will decrease slightly in the first trimester and then return to normal throughout pregnancy. Estrogen increases the amount of thyroid hormone-binding protein in serum, which increases total thyroid hormone levels in the blood. However, measurements of "free" hormones (which are not bound to proteins, representing the active form of hormones) usually remain normal. The thyroid functions normally if $\mathrm{TSH}, \mathrm{T} 4$, and $\mathrm{T} 3$ are all normal in pregnancy. $5 \beta$ subunits of HCG are similar to that of $\mathrm{TSH}^{11}$
HCG in the placenta stimulates TSH receptors, which causes an increase in FT4 and, conversely, decreases TSH in a normal pregnant female. In Grave's disease, thyroid antibodies will stimulate TSH receptors that cause hyperthyroidism. ${ }^{1,12}$

Hyperthyroid in pregnancy without proper management can cause complications for both mother and baby such as the significant risk of premature birth (OR, 1.24 [95\%, CI 1.171.31]; $\mathrm{P}<0.00001)^{10}$

Physical examination showed blood pressure of $136 / 112 \mathrm{mmHg}$, heart pulse of $110 \mathrm{x} / \mathrm{m}$, respiration $24 \mathrm{x} / \mathrm{min}$, and temperature of $38.3^{\circ} \mathrm{C}$. Patients complained of vomiting, diarrhea, and melena, while patients looked weak and somnolent. Exophthalmos was found in the eye, but no enlarged thyroid gland was seen, and the patient was seen screaming frequently. On thyroid test, FT4 levels of 35.18 $\mathrm{pmol} / \mathrm{L}$ and TSH levels $<0.05 \mathrm{uIU} / \mathrm{ml}$ were found. Therefore, the diagnosis of a thyroid crisis was appropriate. ${ }^{9,13}$

The thyroid function test is the first line management to diagnose the thyroid crisis. If high FT4 and low TSH are found along with supporting clinical symptoms, diagnosis of thyroid crisis can be established, and further tests such as detection of Thyroid receptor antibody (TRAb) must be carried out. ${ }^{13}$ Overall, the most common cause $(80-85 \%)$ of maternal hyperthyroidism during pregnancy is Graves' disease, and it occurs in 1 in 1500 pregnant patients. Other common causes of hyperthyroidism are high HCG levels found as hyperemesis gravidarum, which can cause transient hyperthyroidism. ${ }^{5,6}$ Some examples of HCG-mediated hyperthyroidism are gestational transient thyrotoxicosis, hyperemesis gravidarum, and trophoblastic hyperthyroidism. In gestational transient thyrotoxicosis, increased FT4 and decreased TSH are found. However, this condition will return to normal at week 14-18 when HCG returns to normal. ${ }^{13}$

Establishing a clinical diagnosis of thyroid crisis with a Burch-Wartofsky score is very helpful while waiting for laboratory results. ${ }^{14}$ In this patient, a score of 50 was obtained, which means that the patient was categorized as a thyroid crisis. Scores 50 were summed from thermoregulatory dysfunction in patients with a temperature of $38.3^{\circ} \mathrm{C}$ (score 10), pulse 110x/ minute (score 10), gastrointestinal-hepatic dysfunctions as nausea, vomiting (score 10), disorders of the central nervous system as decreased consciousness (score 20). 
Table 2. Diagnosis criteria for thyroid crisis (Burch-Wartofsky, 1993)

\begin{tabular}{|c|c|c|c|}
\hline Criteria & Score & Criteria & Score \\
\hline $\begin{array}{l}\text { Thermoregulatory } \\
\text { dysfunction }\end{array}$ & & $\begin{array}{l}\text { Gastrointestinal-hepatic } \\
\text { dysfunction }\end{array}$ & \\
\hline Temperature $\left({ }^{\circ} \mathrm{C}\right)$ & 5 & Manifestation & 0 \\
\hline $37.8-38.2$ & 10 & Absent & 10 \\
\hline $38.3-38.8$ & 15 & Moderate (diarrhea, abdominal & \\
\hline $38.9-39.3$ & 20 & pain & 20 \\
\hline $39.4-39.9$ & 25 & nausea/vomiting) & \\
\hline$\geq 40$ & 30 & Severe (jaundice) & \\
\hline Cardiovascular & & Central nervous system & \\
\hline Tachycardia (beats/minute) & & disturbance & \\
\hline $100-109$ & 5 & Manifestation & 0 \\
\hline $110-119$ & 10 & Absent & 10 \\
\hline $120-129$ & 15 & Mild (agitation) & 20 \\
\hline $130-139$ & 20 & Moderate (delirium, psychosis, & \\
\hline$\geq 140$ & 25 & extreme lethargy) & 30 \\
\hline Atrial fibrillation & & Severe (seizure, coma) & \\
\hline Absent & 0 & & \\
\hline Present & 10 & & \\
\hline \multicolumn{4}{|l|}{ Congestive heart failure } \\
\hline Absent & 0 & & \\
\hline Mild & 5 & & \\
\hline Moderate & 10 & & \\
\hline Severe & 20 & & \\
\hline Precipitating event & & Total score & \\
\hline Status & 0 & $>45$ & Thyroid crisis \\
\hline Positive & 10 & $25-44$ & Impending \\
\hline Negative & & $<25$ & storm \\
\hline & & & Storm unlikely \\
\hline
\end{tabular}

Other laboratory parameters that increase in thyroid crisis are hyperglycemia, leukocytosis, AST, ALT, hyperbilirubinemia, alkaline phosphatase, lactate dehydrogenase, and creatine kinase. ${ }^{14,15}$ In these patients, an increase in glucose, leukocytosis, AST, ALT, urea, and creatinine.

The patient was diagnosed with suspected sepsis due to her symptoms, such as fever and unstable emotions. It was also supported by the physical examination of pulse $110 \mathrm{x} / \mathrm{min}$, respiration $24 \mathrm{x} / \mathrm{min}$, temperature of $38.3^{\circ} \mathrm{C}$, and high leukocyte lab results of $15.2 \times 103 /$ LL. Bacterial culture was not performed, and CRP, lactate, and procalcitonin levels were not measured because the hospital has not carried out.16 Sepsis can induce thyroid crisis, the initial symptoms of sepsis are very similar to thyroid crisis. ${ }^{8}$

Infection sources must be thoroughly identified by physical examination, urine analysis, chest $\mathrm{X}$-ray, abdominal X-Ray, and history of surgery. ${ }^{16}$ The suspected source of infection in this patient was a urinary tract infection based on complaints of fever, urine analysis results such as $3+$ blood and $1+$ leukocytes, and high leukocytes count of $15.2 \times 103 /$ uL in venous blood.

The possibility of Multiple Organ Dysfunction Syndromes (MODS) due to sepsis was also considered in this patient because the failure of several organs such as the kidneys, liver, and gastrointestinal was found. ${ }^{17}$ Kidney failure is characterized by increased urea and creatinine levels, while liver failure is characterized by increased SGOT and SGPT levels. Also, gastrointestinal failure is characterized by melena in this patient.

Propylthiouracil (PTU) was given to this patient received as therapy at a dose of $3 \times 1$. Anti-thyroid therapy with PTU is the first-line and the most safety 
treatment because it does not cause interference with the fetus compared with Carbimazole/ Methimazole, which can cause congenital abnormalities in infants. Patients with gestational transient thyrotoxicosis do not require anti-thyroid because thyroid hormone will return to normal at week 14 - 18. However, if the clinician is faced with severe patient conditions and difficult to distinguish between Grave disease and gestational transient thyrotoxicosis, the anti-thyroid hormone can be given until the thyroid hormone return to normal levels. ${ }^{11}$

The patient was given Propranolol $3 \times 10 \mathrm{mg}$ to reduce tachycardia and increased blood pressure. ${ }^{13}$

The administration of Cefixime to the patient is the recommended antibiotic for the treatment of sepsis. $^{16}$

\section{CONCLUSIONS AND SUGGESTIONS}

The final diagnosis of this patient is a thyroid crisis and sepsis in the first trimester of pregnancy. Detection of thyroid antibody receptor (TRAb) must be carried out to distinguish between Grave's disease and hyperthyroidism due to pregnancy (transient hyperthyroid).

\section{REFERENCES}

1. Fujiko M. Hipertiroid dalam kehamilan. Divisi Fetomaternal, Departemen Obgin FK UNHAS/RS Dr.Wahidin Sudirohusodo. Makassar. 2016; 1-29.

2. Shomon M. Symptoms of hyperthyroidism. Agustus 2018. www.verywellhealth.com. (accessed August 23, 2018)

3. Andersen $\mathrm{SL}$, Olsen J, Carlé A, Laurberg $\mathrm{P}$. Hyperthyroidism incidence fluctuates widely in and around pregnancy and is at variance with some other autoimmune diseases: A Danish population-based study. 2018; 100: 1164-71.
4. Thobbi VA, Majeed S. Prevalence of thyroid disorder in pregnancy. Int J Tech Res Appl, 2016; 4(2): 2320-8163.

5. American Thyroid Association. Pregnancy and thyroid disease. 2017. www. Thyroid.org. (accessed July 31, 2018)

6. Newson L. Hyperthyroidism in pregnancy. 23 December 2015. https://patient.info/doctor/ Hyperthyroidism in pregnancy. (accessed August 25, 2018)

7. Newson L. Hyperthyroid crisis. 23 December 2015. https:// patient.info/doctor/hyperthyroid-crisis-thyrotoxic-storm. (accessed August 25, 2018)

8. Yeh $C-Y, Y u$ W-L. A case report of thyroid storm induced by acute sepsis. J Acute Dis, 2016; 5(2): 160-1

9. Moore K. Thyroid storm: Causes, symptoms, and diagnosis. Healthline, 2017. https://www.healthline. com. (accessed August 23, 2018)

10. Sheehan PM, Nankervis A, Júnior EA, Da F, Costa S. Maternal thyroid disease and preterm birth: Systematic review and meta-analysis. 2018; 100: 4325-31.

11. Aggarwal R, Chugh P. Management of hyperthyroidism in pregnancy. 2016; 5(1): 1-5.

12. Glinoer D. The regulation of thyroid function in pregnancy: pathways of endocrine adaptation from physiology to pathology. Endocr Rev, 1997; 18(3): 404-433.

13. Williamson R, McLaren J, Beckett G, Forbes S, Brown R. Guidelines for the management of thyrotoxicosis. https://static1.squarespace.com (accessed August 25, 2018)

14. Suhartoyo T. Krisis tiroid. Sendomet 2018. Semarang, Penerbit PAPDI Semarang, 2018; 1 - 6.

15. Wei C, Myint AA. Hyperemesis gravidarum and gestational transient hyperthyroidism: A case report. Journal of Gynecology and Obstetrics, 2013; 1(2): 7-10.

16. NICE guidline. Sepsis: Recognition, diagnosis and early management. https://www.nice.org.uk (accessed August 24, 2018)

17. Spapen HD, Jacobs R, Honore PM. Sepsis induced multi organ dysfunction syndrome-a mechanistic approach. J Emerg \& Crit Care Med, 2017; 1: 2. 